\title{
Influence of particle size and chemistry on the cloud nucleating properties of aerosols
}

\author{
P. K. Quinn ${ }^{1}$, T. S. Bates ${ }^{1}$, D. J. Coffman ${ }^{1}$, and D. S. Covert ${ }^{2}$ \\ ${ }^{1}$ NOAA Pacific Marine Environmental Laboratory, Seattle, WA 98115, USA \\ ${ }^{2}$ Joint Institute for the Study of the Atmosphere and Oceans, University of Washington, Seattle, WA 98105, USA
}

Received: 28 September 2007 - Published in Atmos. Chem. Phys. Discuss.: 5 October 2007

Revised: 10 January 2008 - Accepted: 20 January 2008 - Published: 26 February 2008

\begin{abstract}
The ability of an aerosol particle to act as a cloud condensation nuclei $(\mathrm{CCN})$ is a function of the size of the particle, its composition and mixing state, and the supersaturation of the cloud. In-situ data from field studies provide a means to assess the relative importance of these parameters. During the 2006 Texas Air Quality - Gulf of Mexico Atmospheric Composition and Climate Study (TexAQSGoMACCS), the NOAA RV Ronald H. Brown encountered a wide variety of aerosol types ranging from marine near the Florida panhandle to urban and industrial in the HoustonGalveston area. These varied sources provided an opportunity to investigate the role of aerosol sources and chemistry in the potential activation of particles to form cloud droplets. Measurements were made of $\mathrm{CCN}$ concentrations, aerosol chemical composition in the size range relevant for particle activation in warm clouds, and aerosol size distributions. Variability in aerosol composition was parameterized by the mass fraction of Hydrocarbon-like Organic Aerosol (HOA) for particle diameters less than $200 \mathrm{~nm}$ (vacuum aerodynamic). The HOA mass fraction in this size range was lowest for marine aerosol and highest for aerosol sampled close to anthropogenic sources. Combining all data from the experiment reveals that composition (defined by HOA mass fraction) explains $40 \%$ of the variance in the critical diameter for particle activation at the instrumental supersaturation $(S)$ of $0.44 \%$. Correlations between HOA mass fraction and aerosol mean diameter show that these two parameters are essentially independent of one another for this data set. We conclude that, based on the variability of the HOA mass fraction observed during TexAQS-GoMACCS, variability in particle composition played a significant role in determining the fraction of particles that could activate to form cloud droplets. Using a simple model based on Köhler theory and
\end{abstract}

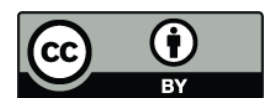

Correspondence to: P. K. Quinn (patricia.k.quinn@noaa.gov) the assumption that $\mathrm{HOA}$ is insoluble, we estimate the degree to which calculated $\mathrm{CCN}$ concentrations are under- or overestimated if the variability in the HOA mass fraction that was observed during TexAQS-GoMACCS is neglected. The percent under- or overestimation in the $\mathrm{CCN}$ concentration is related to the source of the aerosol. Relative to the mean HOA mass fraction of $0.4 \pm 0.2$ (average $\pm 1 \sigma$ standard deviation) for the entire experiment, $\mathrm{CCN}$ concentrations are underestimated by up to $50 \%$ (at $0.22 \% \mathrm{~S}$ ) for aerosol sampled far from anthropogenic source regions as it had a lower HOA mass fraction and overestimated by up to $50 \%$ for organicrich aerosol sampled near the source as it had a higher HOA mass fraction.

\section{Introduction}

In both the IPCC Third and Fourth Assessment Reports (IPCC, 2001, 2007), aerosol indirect forcing is assigned the largest source of uncertainty among all climate forcing mechanisms. In the Fourth Assessment Report, the radiative forcing due to the first indirect or cloud albedo effect is given a low level of scientific understanding for liquid water clouds. The cloud albedo effect occurs as the portion of aerosol that forms cloud condensation nuclei (CCN) increases in concentration and modifies the microphysical properties of clouds. For a fixed liquid water content, an increase in $\mathrm{CCN}$ will lead to enhanced cloud droplet number concentration, decreased droplet size, and enhanced cloud albedo (e.g., Twomey, 1977). The ability of any particle within a population of aerosol particles to act as a CCN and nucleate cloud droplets is a function of its size and chemical composition as well as the supersaturation of the air parcel. For a distribution of particles the spectrum of $\mathrm{CCN}$ with respect to supersaturation depends on the median diameter, standard deviation, number concentration and the internal mixing state. Composition affects $\mathrm{CCN}$ activity by determining molecular weight

Published by Copernicus Publications on behalf of the European Geosciences Union. 

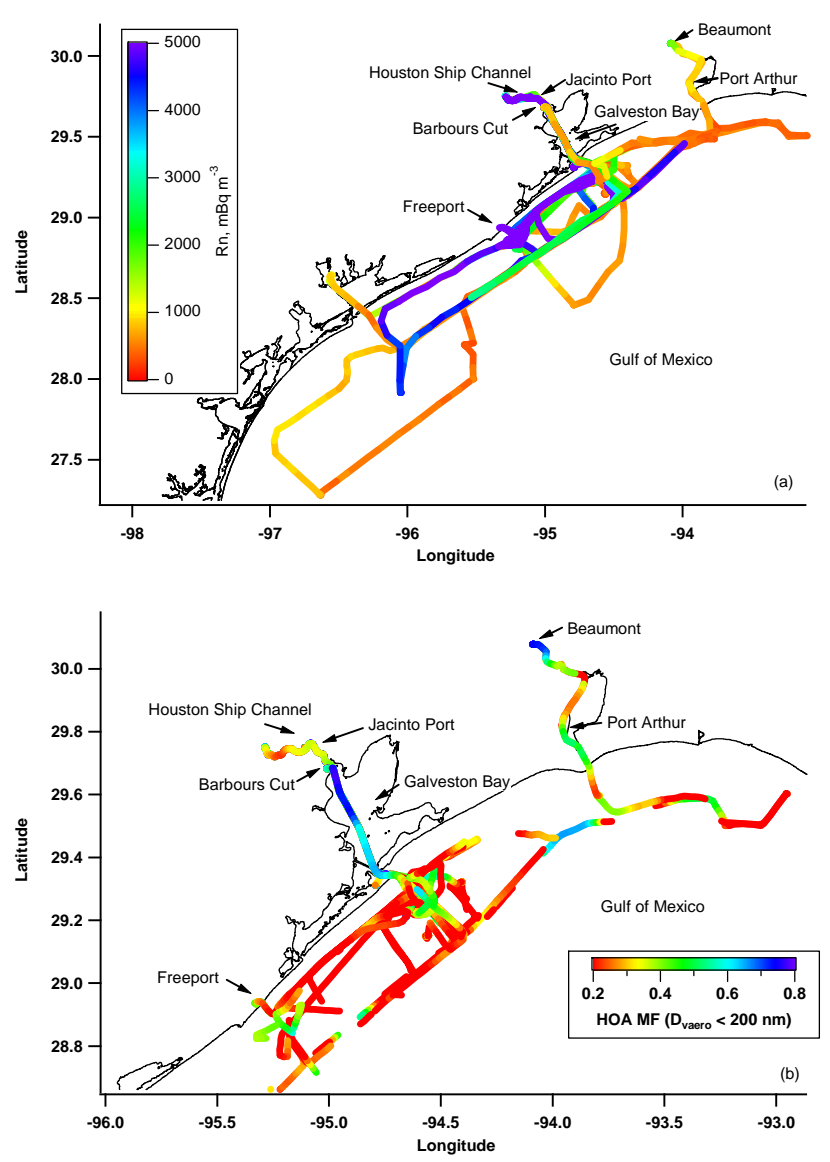

Fig. 1. Cruise track in the GoMACCS study region colored by (a) $\mathrm{Rn}$ and (b) HOA mass fraction. GoMACCS took place from late July to mid-September, 2006. The portion of the cruise track from Charleston, SC to the GoMACCS study region is not shown.

of the solute within a cloud droplet, density, solubility, degree of dissociation, and surface tension. Understanding how these parameters influence particle activation to form $\mathrm{CCN}$ is essential to improving estimates of cloud droplet formation by global climate models (e.g., Abdul-Razzak and Ghan, 2002; Fountakis and Nenes, 2005).

The relative importance of aerosol parameters (size distribution and composition) and dynamical parameters (updraft velocity and liquid water content) in controlling cloud albedo has been the subject of many recent studies. Modeling studies have investigated links between aerosol parameters and cloud microphysical properties. Using a cloud parcel model, Feingold (2003) found that the aerosol number concentration was consistently important for determining cloud drop effective radius while the importance of other parameters varied for different conditions. Modeling studies have also investigated the influence of selected organic compounds and inorganic/organic mixtures on cloud drop number concentration (e.g., Shantz et al., 2003; Nenes et al., 2002; Mircea et al., 2002). A comparison of these studies revealed that predicted changes in droplet concentration due to the presence of organics in aerosols varied from $-86 \%$ to $+110 \%$ (Ervens et al., 2005). This wide range is a result of variability in the treatment of composition parameters in the models including solubility, molecular weight, and surface tension suppression. Most of these previous studies focused on the impact of organic acids and water soluble organic carbon. Petzold et al. (2005) investigated carbonaceous particles produced by combustion and found that only a small fraction activated to $\mathrm{CCN}$. Furthermore, a high fraction of non-volatile organic matter in the particles caused a considerable increase in the activation diameter.

Measurements from recent field campaigns have been used to assess the importance of particle size versus variability in chemical composition in determining $\mathrm{CCN}$ concentrations. Based on measurements of a limited range of aerosol composition encountered at a non-urban site in Germany, Dusek et al. (2006) reported that variation in the size distribution was able to explain 84 to $96 \%$ of the variance in measured CCN concentrations. Measurements of a broader range of aerosol composition during several aircraft campaigns indicated that a knowledge of both size and composition are required to accurately deduce $\mathrm{CCN}$ concentrations in the absence of $\mathrm{CCN}$ measurements (Hudson, 2007). Here we investigate the roles of aerosol size and composition in determining $\mathrm{CCN}$ concentrations based on measurements made during the 2006 Texas Air Quality - Gulf of Mexico Atmospheric Composition and Climate Study (TexAQS-GoMACCS; hereafter GoMACCS) onboard the NOAA RV Ronald H. Brown.

GoMACCS took place in 2006 from the end of July to the middle of September. Photochemical pollution and regional haze are common during this time of year in Texas. Between 27 July and 11 September 2006, the NOAA RV Ronald $H$. Brown encountered a wide variety of aerosol types ranging from marine over the Atlantic Ocean near the Florida panhandle to urban and industrial in the Houston-Galveston area (Fig. 1). This wide variability in aerosol sources and chemical composition provided an opportunity to investigate the role of chemistry in the activation of particles to form cloud droplets. For this purpose, measurements were made of the $\mathrm{CCN}$ number concentration at five different supersaturations, aerosol chemical composition, and the particle size distribution.

For realistic updraft velocities and corresponding supersaturations of warm clouds, composition effects on cloud drop activation will be most pronounced for particles with diameters between about 40 and $200 \mathrm{~nm}$ (e.g., McFiggans et al., 2006). Regardless of composition, smaller diameter particles will not activate under these conditions while larger diameter particles will. Hence, it is this intermediate size range that is of interest when determining composition effects on $\mathrm{CCN}$ activation. It is significant, then, that this size range $(<200 \mathrm{~nm})$ often contains a large mass fraction of particulate organic matter (POM). Furthermore, the POM in this size range tends to be composed of relatively low solubility 
hydrocarbon-like organic aerosol (HOA) while POM measured at larger diameters is composed of oxygenated organic aerosol (OOA) (e.g., Zhang et al., 2005a, b; Alfarra et al., 2004; Allan et al., 2003). HOA in the smaller size range may lead to fewer particles activating to form $\mathrm{CCN}$ compared to the case where the POM is composed only of OOA (McFiggans et al., 2006).

In this study, we relate the HOA mass fraction $\left(\mathrm{HOA}_{\mathrm{MF}}\right)$ for vacuum aerodynamic diameters $\left(D_{\text {vaero }}\right)<200 \mathrm{~nm}$ measured during GoMACCS to the critical diameter for activation $\left(D_{c}\right)$. (A $D_{\text {vaero }}$ of $200 \mathrm{~nm}$ corresponds to a geometric diameter of $133 \mathrm{~nm}$ for a spherical particle with a density of 1.5.) The goal of this analysis is to examine the influence of particle composition on $\mathrm{CCN}$ activation for the variability in the aerosol observed during this experiment. In addition, the degree of under- or overestimation of the $\mathrm{CCN}$ concentration due to neglecting the variability in HOA mass fraction observed during GoMACCS is calculated using a simple model based on Köhler theory.

\section{Methods}

\subsection{Aerosol sampling inlet}

Sample air for all aerosol measurements was drawn through a 6-m mast. The entrance to the mast was $18 \mathrm{~m}$ above sea level and forward of the ship's stack. The mast was automatically rotated into the relative wind to maintain nominally isokinetic flow and minimize the loss of supermicrometer particles. Air entered the inlet through a $5 \mathrm{~cm}$ diameter hole, passed through a $7^{\circ}$ expansion cone, and then into the $20 \mathrm{~cm}$ inner diameter sampling mast. The flow through the mast was $1 \mathrm{~m}^{3} \mathrm{~min}^{-1}$. The transmission efficiency of the inlet for particles with aerodynamic diameters less than $6.5 \mu \mathrm{m}$ (the largest size tested) is greater than 95\% (Bates et al., 2002).

The bottom $1.5 \mathrm{~m}$ of the mast were heated to establish a stable reference relative humidity $(\mathrm{RH})$ for the sample air of $60 \pm 5 \%$. On average, the aerosol was heated $2.5^{\circ} \mathrm{C}$ above the ambient temperature. Stainless steel tubes extending into the heated portion of the mast were connected to downstream aerosol instrumentation with either conductive silicon tubing or stainless steel tubing for analysis of organic aerosol.

The data reported here are based on air that was sampled only when the particle number concentration, the relative wind speed, and the relative wind direction all indicated that there was no possibility of contamination from the ship's stack.

\section{$2.2 \mathrm{CCN}$ concentration}

A Droplet Measurement Technologies (DMT) CCN counter was used to determine $\mathrm{CCN}$ concentrations at supersaturations, $S$, of $0.22,0.44,0.65,0.84$, and $1.0 \%$. Details concerning the characteristics of the DMT CCN counter can be found in Roberts and Nenes (2005) and Lance et al. (2006).
A multijet cascade impactor (Berner et al., 1979) with a 50\% aerodynamic cutoff diameter of $1 \mu \mathrm{m}$ was upstream of the CCN counter. The instrument was operated in two different modes. When the ship was located close to urban, industrial, or marine vessel sources such that aerosol concentrations fluctuated rapidly, a single supersaturation setting of $0.44 \%$ was often used. Away from sources when aerosol conditions were more stable, the five different supersaturations were cycled through over a $30 \mathrm{~min}$ period. For the multiple supersaturation mode, the first $2 \mathrm{~min}$ of each $6 \mathrm{~min}$ period were discarded so that only periods with stable supersaturations are included in the analyzed data set.

The $\mathrm{CCN}$ counter was calibrated before and during the experiment as outlined by Lance et al. (2006). An $\left(\mathrm{NH}_{4}\right)_{2} \mathrm{SO}_{4}$ aqueous solution was atomized with dry air, passed through a diffusional drier, diluted and then introduced to a Scanning Mobility Particle Sizer (SMPS, TSI). The resulting monodisperse aerosol stream was sampled simultaneously by the CCN counter and a water-based Condensation Particle Counter (WCPC, TSI) in order to determine the average activated fraction $(\mathrm{CCN} / \mathrm{CN})$. This procedure was repeated for a range of particle sizes and instrumental supersaturations. Using this procedure, the instrument supersaturation is equal to the critical supersaturation of the particle obtained from the activation curve for an activated fraction of 50\%. The critical supersaturation for a given particle size was calculated from Köhler theory (e.g., Fitzgerald and Hoppel, 1984). The supersaturations reported in the text are based on the calibrations and not the instrumental readout which disregards thermal efficiency. The difference between the calibrated values and those reported by the instrument were similar to the difference found by Lance et al. (2006). The uncertainty associated with the CCN number concentrations is estimated to be less than $\pm 10 \%$ (Roberts and Nenes, 2005). Uncertainty in the instrumental supersaturation is less than $\pm 1 \%$ for the operating conditions of this experiment (Roberts and Nenes, 2005).

\subsection{Particle number size distributions}

Size distributions from 20 to $200 \mathrm{~nm}$ and from 200 to $800 \mathrm{~nm}$ in geometric diameter were measured with two parallel differential mobility particle sizers (DMPS, University of Vienna (Winklmeyer, 1991) short and medium length columns, respectively) coupled to condensation particle counters (CPC model $3760 \mathrm{~A}, \mathrm{TSI}$ ). The relative humidity of the sheath air for both instruments was controlled such that the measurement RH was approximately $60 \%$. Mobility distributions were collected every $5 \mathrm{~min}$. Details of the mobility distribution measurements and inversion methods are given by Bates et al. (2004) and Stratmann and Wiedensohler (1997).

Size distributions from 0.9 to $10 \mu \mathrm{m}$ in aerodynamic diameter were measured with an aerodynamic particle sizer (APS model 3321, TSI). Modifications were made to the APS to reduce internal heating of the sample air so that the 
measurement RH was close to $60 \%$. Size distributions were collected every 5 min to match the DMPS scan time. APS size distributions were converted from aerodynamic to geometric diameters using densities based on the measured, time-dependent chemical composition (Quinn et al., 2002). The uncertainty associated with the number concentration derived from the size distribution measurements is estimated to be $\pm 18 \%$ (Quinn et al., 2004).

Geometric number mean diameters $\left(D_{g n}\right)$ were calculated from a lognormal fit to each measured size distribution. If the size distribution contained both an Aitken and accumulation mode, the fit was performed on the smaller Aitken mode. If only an accumulation mode was present in the submicrometer size range, it was used to determine $D_{g n}$.

\subsection{Particle chemical composition}

Concentrations of submicrometer non-refractory $\mathrm{NH}_{4}^{+}, \mathrm{SO}_{4}^{=}$, $\mathrm{NO}_{3}^{-}$, and POM were measured with a Quadrupole Aerosol Mass Spectrometer (Q-AMS, Aerodyne Research Inc., Billerica, MA). The AMS was downstream of a multijet cascade impactor with a 50\% cutoff diameter of $1 \mu \mathrm{m}$ (Berner et al., 1979). Sample air reaching the AMS was at an RH of $52 \pm 3.2 \%$. The species measured by the AMS are referred to as non-refractory (NR) and are defined here as all the chemical components that vaporize at $550^{\circ} \mathrm{C}$. These species include most organic components, inorganics such as ammonium nitrate and ammonium sulfate salts but not mineral dust, elemental carbon, or sea salt. The POM aerosol was divided into two fractions, a hydrocarbon-like organic aerosol (HOA) and an oxygenated organic aerosol (OOA) using a multiple linear regression of $\mathrm{m} / z 57$ and $\mathrm{m} / \mathrm{z} 44$, respectively (Zhang et al., 2005a). The ionization efficiency of the AMS was calibrated every few days with dry monodisperse $\mathrm{NH}_{4} \mathrm{NO}_{3}$ particles using the procedure described by Jimenez et al. (2003). The instrument operated on a $5 \mathrm{~min}$ cycle with the standard AMS aerodynamic lens (Canagaratna et al., 2007).

The collection efficiency of the AMS is the product of the transmission of particles through the aerodynamic lens $\left(E_{L}\right)$, the efficiency with which particles are focused by the lens and directed to the impactor-vaporizer $\left(E_{S}\right)$, and the degree to which particles are vaporized and analyzed versus bounced off the impactor-vaporizer $\left(E_{B}\right)$ (Huffman et al., 2005). Particle losses due to transmission through the lens were corrected by using the DMPS and APS-measured size distributions. This correction added, on average, $14 \pm 8 \%$ to the AMS total mass. Based on beam width probe data, there was no indication of particle loss due to $E_{S} . E_{B}$ is a function of particle water content and chemical composition (Allan et al., 2003). Comparison of the size corrected $\left(E_{L}\right)$ AMS NR sulfate with sulfate simultaneously measured with a particleinto-liquid-sampler coupled to an ion chromatograph (PILSIC) indicates that $E_{B}$ varied from 1 for acidic sulfate (ammonium to sulfate molar ratio of $<0.5$ ) to 0.54 for ammonium sulfate. Therefore, $E_{B}$ was assigned to each 5 min sample based on the AMS ammonium to sulfate molar ratio with $E_{B}$ as an exponential function of the ammonium to sulfate molar ratio varying from 0.54 to 1 for ammonium to sulfate molar ratios of 2 to 0.5 . There was no indication from the AMS mass size distributions that the ammonium to sulfate molar ratio varied as a function of size over the accumulation mode size range. A linear regression of $5 \mathrm{~min}$ transmission and bounce corrected AMS sulfate concentrations versus PILSIC sulfate concentrations yielded a slope of 0.95 and an $r^{2}$ of 0.81 . The uncertainty in the AMS concentration measurements during GoMACCS was estimated at $\pm 20 \%$.

\subsection{Radon}

Radon was detected with a dual-flow loop, two-filter detector (Whittlestone and Zahorowski, 1998). The radon detector was standardized using radon emitted from a permeation tube. Background counts were measured with the air flow set to zero.

\section{Results}

To relate aerosol sources and transport to $\mathrm{CCN}$ formation, the data set was segregated in two ways. The first was based on geographical location and includes both offshore and inland sampling sites (Fig. 1). The offshore locations include a portion of the cruise track in the Atlantic Ocean as the ship transited from Charleston, SC to the GoMACCS study area. Additional offshore locations include the Gulf of Mexico during the initial transit to the Houston-Galveston area and subsequent visits over the course of the experiment. Inland locations include Galveston Bay which is the thoroughfare for ships transiting from the Gulf of Mexico to Houston, the Houston Ship Channel which is heavily impacted by marine vessel traffic and petrochemical and other industrial activities, Barbours Cut which is located at the entrance to the east-west portion of the ship channel and is the site of a major container and cruise terminal, Jacinto Port which is located on the north side of the Houston Ship Channel, and Freeport which is the site of a large chemical plant.

The second data sorting procedure was based on surface wind direction and radon concentrations. Radon was used in the data analysis to differentiate between sampled air from northerly flow that had been over the continent during the past day and "background" southerly flow from the Gulf of Mexico toward the continent. The radon threshold between continental and "background" air was $1000 \mathrm{mBq} \mathrm{m}^{-3}$ (Fig. 1). This sorting led to three categories 1) GulfSoutherly Flow which includes samples taken in the Gulf of Mexico during southerly flow and low radon concentrations and, hence, represents background air entering Texas, 2) Inland Texas-Southerly Flow which also includes samples taken during southerly flow and low radon concentrations 

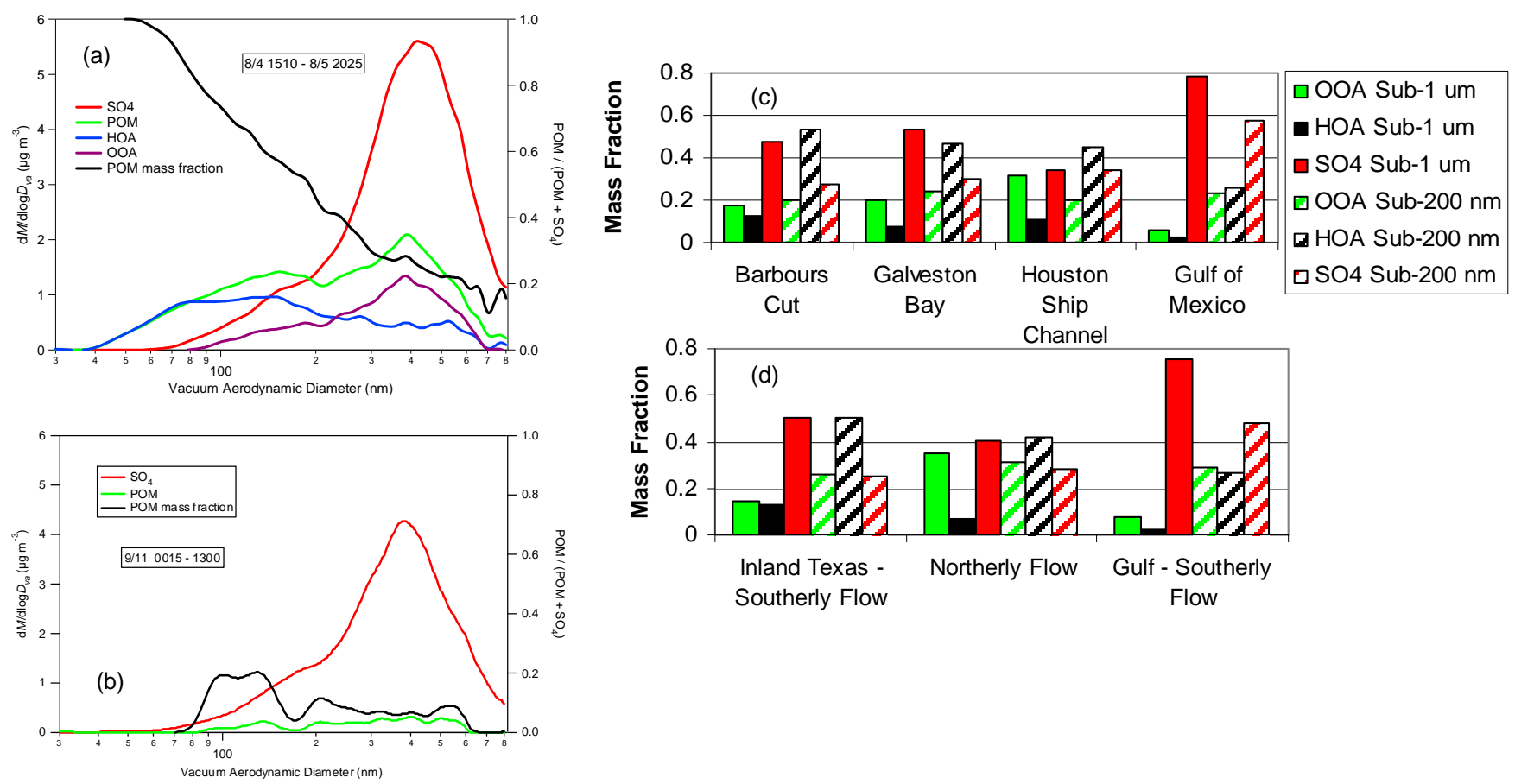

Fig. 2. Average size distribution of the chemical components and POM mass fraction for (a) 8/4 15:10 to 8/5 20:25 UTC at Barbours Cut and (b) 9/11 00:15 to 13:00 UTC in the Gulf of Mexico. Also shown are mass fractions averaged over the submicrometer and sub-200 nm size ranges for (c) geographical sampling locations and (d) wind-radon regimes.

but from inland locations and, thus, represents background air entering Texas plus local sources near the sampling site, and 3) Northerly Flow which includes samples taken during northerly flow and high radon concentrations and, therefore, represents continentally-influenced air masses impacted by both distant and local sources.

\subsection{Aerosol composition and size during GoMACCS}

\subsubsection{Aerosol composition}

Previously reported AMS measurements indicate several general features concerning the regional distribution of POM in terms of particle size and composition (Canagaratna et al., 2007). In general, in both rural and urban environments, the POM that occurs in the accumulation mode size range (200 to $500 \mathrm{~nm} D_{\text {vaero }}$ ) has a mass spectra that is characteristic of oxygenated organic molecules (e.g., Zhang et al., 2005a, b; Alfarra et al., 2004; Allan et al., 2003; Boudries et al., 2004). This OOA is typically internally mixed with inorganic species such as ammonium sulfate salts (e.g., Cubison et al., 2005). However, in urban environments there often is a second mode of POM with a smaller average mass mean diameter $\left(D_{\text {vaero }} \sim 100 \mathrm{~nm}\right)$ that has a mass spectrum characteristic of hydrocarbons (Allan et al., 2003; Drewnick et al., 2004; Zhang et al., 2005b) and that is very similar to what has been measured in fresh vehicle exhaust (Canagaratna et al., 2004; Schneider et al., 2005).

Results from GoMACCS are consistent with these previously reported measurements. The mass fraction of HOA for $D_{\text {vaero }}<200 \mathrm{~nm}$ often exceeded 0.5 for the inland portions of the cruise track (Galveston Bay, Barbours Cut, Beaumont, and Port Arthur) where urban and marine vessel emissions were most pronounced (Fig. 1). Size distributions of the POM components, sulfate, and POM mass fraction are shown in more detail in Fig. 2a for a period when the ship was docked for thirty hours at Barbours Cut on 4 and $5 \mathrm{Au}-$ gust. The POM mass fraction is calculated as the mass concentration of POM divided by the total mass measured by the AMS. AMS size distributions averaged over this period show the occurrence of POM in the accumulation mode at about one third the mass concentration of sulfate. The majority of this POM was OOA. In contrast, POM dominated the Aitken mode (mass mean $D_{\text {vaero }}$ of $160 \mathrm{~nm}$ ) and was composed primarily of HOA. The POM mass fraction was 0.45 at $D_{\text {vaero }}=200 \mathrm{~nm}$ and increased steadily to near one at $D_{\text {vaero }}$ of $50 \mathrm{~nm}$.

Figure $2 \mathrm{~b}$ shows the same information for a $13 \mathrm{~h}$ period on 11 September when the ship was offshore in the Gulf of Mexico. During this period, local winds were from the south at less than $5 \mathrm{~m} \mathrm{~s}^{-1}$ and radon concentrations were low indicating that the sampled air mass had not had recent contact 
with land. In this case, sulfate dominated the submicrometer mass at all sizes such that the POM mass fraction was 0.25 or less for all particle diameters. The majority of the sulfate was most likely due to emissions from the large number of marine vessels in the upwind region (Bates et al., in preparation, 2008).

To compare the degree to which HOA contributed to the sub-200 nm mass versus the entire submicrometer size range, HOA, OOA, and sulfate mass fractions were calculated for these two size ranges. Mass fractions were calculated as the mass of the component divided by the total mass measured by the AMS. Average mass fractions for the periods spent in Barbours Cut, Galveston Bay, the Houston Ship Channel, and the Gulf of Mexico are shown in Fig. 2c. On average, for the inland sampling locations, sulfate dominated the submicrometer mass with OOA having the second largest mass fraction. Average submicrometer mass fractions of HOA were less than 0.14 for each of the inland locations (Barbours Cut: 0.13 \pm 0.11 , Galveston Bay: $0.07 \pm 0.08$, Houston Ship Channel: $0.11 \pm 0.08$ ). The sub$200 \mathrm{~nm}$ mass fractions look very different, however, with average $\mathrm{HOA}_{\mathrm{MF}}$ of $0.53 \pm 0.20$ at Barbours Cut, $0.47 \pm 0.21$ in Galveston Bay, and 0.45 \pm 0.16 in the Houston Ship Channel. Relative to the inland sampling locations, both submicrometer and sub-200 nm $\mathrm{HOA}_{\mathrm{MF}}$ were lower for the offshore trips into the Gulf of Mexico. Averaged over all the times the ship spent in the Gulf of Mexico, the submicrometer $\mathrm{HOA}_{\mathrm{MF}}$ was $0.02 \pm 0.03$ compared to a sub- $200 \mathrm{~nm}$ value of $0.26 \pm 0.19$. Figure 2a shows that not only the mass fractions but also the size distributions of HOA, OOA, sulfate are different within the sub- $200 \mathrm{~nm}$ size range. Sulfate and OOA tail into this size range meaning that their largest concentrations occur at large diameters while HOA peaks in this size range and, therefore, has more broadly distributed concentrations throughout the size range.

Average submicrometer and sub- $200 \mathrm{~nm}$ mass fractions are shown for the different wind-radon regimes in Fig. 2d. For all three regimes, the submicrometer mass is dominated by sulfate with OOA having the second largest average mass fraction. However, for the Inland Texas - Southerly Flow regime, $\mathrm{HOA}_{\mathrm{MF}}$ and $\mathrm{OOA}_{\mathrm{MF}}$ are nearly the same reflecting the close proximity of the ship to anthropogenic sources. The $\mathrm{OOA}_{\mathrm{MF}}$ is about three times greater than the $\mathrm{HOA}_{\mathrm{MF}}$ for the Northerly Flow regime reflecting the mix of distant and local sources in this category. Submicrometer average mass fractions for the Gulf-Southerly Flow regime are similar to the "Gulf of Mexico" category in Fig. 2b. For the two wind-radon regimes impacted by continental emissions, HOA dominated the sub- $200 \mathrm{~nm}$ size range. The $\mathrm{HOA}_{\mathrm{MF}}$ for this size range averaged $0.51 \pm 0.21$ for the Inland TexasSoutherly Flow regime and $0.42 \pm 0.23$ for the Northerly Flow regime.

In summary, the particle size range most sensitive to composition effects in $\mathrm{CCN}$ activation was, for much of the experiment, dominated by HOA, an organic component whose mass spectrum is similar to those of diesel exhaust, lubricating oil, and freshly emitted traffic aerosols (Zhang et al., 2005a). In contrast, the organics within particles with $D_{\text {vaero }}>200 \mathrm{~nm}$ were dominated by a component with a mass spectrum indicative of aged, oxygenated organic aerosols. In the following analysis, the mass fraction of HOA for $D_{\text {vaero }}<200 \mathrm{~nm}$ was used to represent the variability of aerosol composition during the GoMACCS experiment because of its prevalence in this size range and its limited solubility which is expected to impact the $\mathrm{CCN}$ activation process.

\subsubsection{Aerosol number size distribution}

The geometric mean number diameter based on a lognormal fit of each measured size distribution was used to indicate the variability of particle size during GoMACCS. Only number modes contained in the submicrometer size range were considered. The geometric standard deviation, $\sigma_{s g}$, or width of the mode also has been shown in modeling studies to affect cloud drop number concentrations (Feingold, 2003). At high particle concentrations, for a given $D_{g n}$ and total number concentration, increases in $\sigma_{s g}$ lead to a decrease in the drop concentration because as the mode becomes broader, relatively more large particles are present and activated which leads to a suppression of the supersaturation. The decrease in supersaturation may lead to fewer particles being activated to $\mathrm{CCN}$ especially in polluted air masses dominated by larger particles. Near-source sampling locations (Barbours Cut and Houston Ship Channel) had high frequencies of lower values of $D_{g n}(<70 \mathrm{~nm})$ (Fig. 3a). Larger frequencies of $D_{g n}>70 \mathrm{~nm}$ occurred for Galveston Bay and Gulf of Mexico which are more distant from anthropogenic continental sources. Correspondingly, the local sources picked up under Inland-Texas-Southerly Flow conditions led to a high frequency of smaller $D_{g n}$ values while Gulf-Southerly Flow conditions had a high frequency of $D_{g n}>70 \mathrm{~nm}$. The Northerly Flow regime which included both local and more distant continental sources had more broadly distributed values of $D_{g n}$.

Both the sub-200 nm HOA mass fraction and the mean diameter displayed general trends in the context of sampling location and wind direction-radon regimes as discussed above. There was no significant correlation between these two parameters, however, for either the individual sample categories or for the overall data set. The coefficient of determination, $r^{2}$, for $\mathrm{HOA}_{\mathrm{MF}}$ versus $D_{g n}$ for the whole experiment was 0.10 indicating that the $\mathrm{HOA}_{\mathrm{MF}}$ could only explain about $10 \%$ of the variance in $D_{g n}$. 

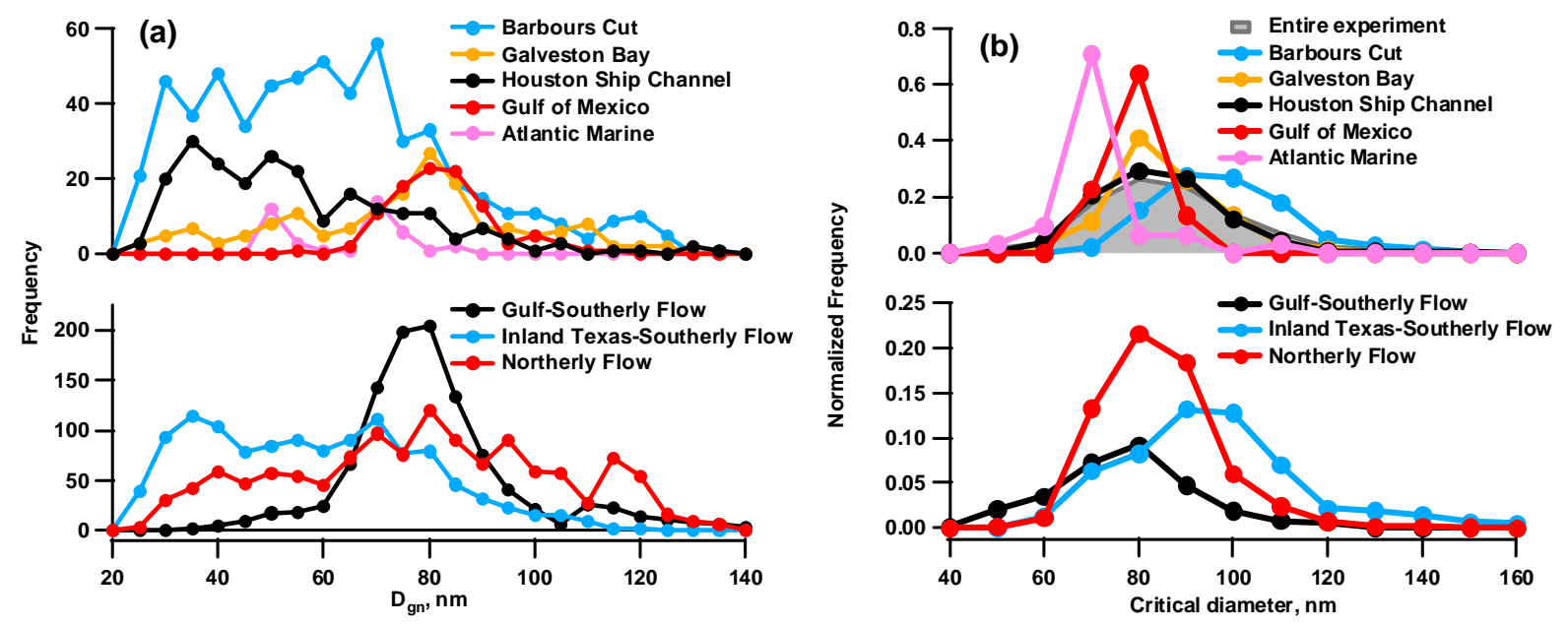

Fig. 3. Frequency distributions based on aerosol sampled at different geographical locations and the three wind-radon regimes of (a) the geometric mean diameter $\left(D_{g n}\right)$ and (b) critical diameter at $S=0.44 \%$.

\subsection{Impact of composition on $\mathrm{CCN}$ formation}

\subsubsection{Calculation of critical diameter}

The correlation between critical diameter for $\mathrm{CCN}$ activation $\left(D_{c}\right)$ and aerosol composition was used to quantify the impact of composition on particle activation. $D_{c}$ is defined in this analysis as the diameter at which

$\mathrm{CCN}_{\text {measured }}=\mathrm{CNC}_{\text {integrated }}$

where $\mathrm{CNC}_{\text {integrated }}$, the integrated condensation nuclei concentration, was found by integrating the number-size distributions from the largest diameter measured down to the diameter where the above equation was satisfied. Uncertainty in Eq. (1) and, therefore in $D_{c}$, is estimated at $\pm 20 \%$ based on a quadrature of the errors in the number concentrations derived from the $\mathrm{CCN}$ counter $( \pm 10 \%)$ and the measured size distributions $( \pm 18 \%)$. The actual uncertainty in $D_{c}$ will deviate from this estimate depending on the slope of the size distribution around $D_{c}$, i.e., whether $D_{c}$ is greater than or less than $D_{g n}$.

Normalized frequency distributions of $D_{c}$ are shown at $S=0.44 \%$ in Fig. $3 \mathrm{~b}$. Values of $D_{c}$ calculated for the entire experiment extended up to near $170 \mathrm{~nm}$. The highest frequency of small values of $D_{c}(<80 \mathrm{~nm})$ corresponded to measurements of marine aerosol made as the ship transited from South Carolina to the study region (denoted here as Atlantic Marine). Locations with a high frequency of $D_{c}$ between 70 and $90 \mathrm{~nm}$ included the Gulf of Mexico and Galveston Bay. These locations are impacted by anthropogenic emissions but are not immediately downwind. Values of $D_{c}$ greater than $90 \mathrm{~nm}$ were most frequent for inland sampling locations next to urban and industrial sources (Barbours Cut and the Houston Ship Channel). A comparison of values

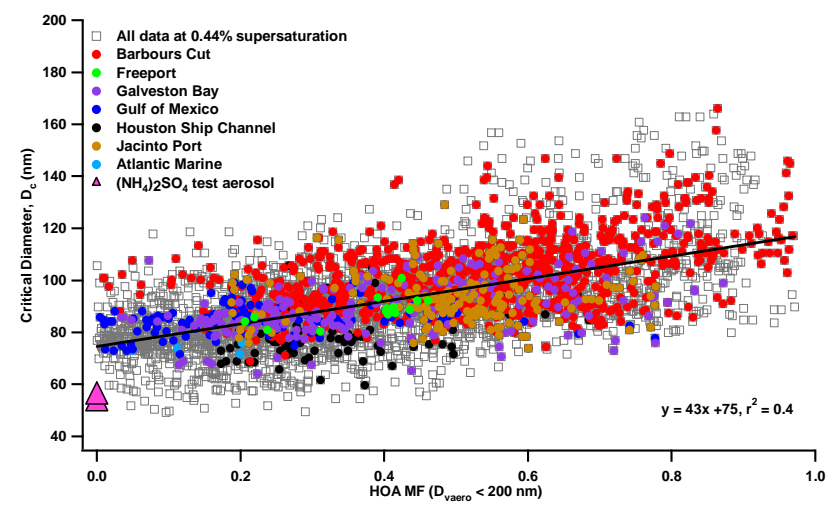

Fig. 4. $\mathrm{HOA}_{\mathrm{MF}}$ of the AMS mass for the size range $D_{\text {vaero }}<200 \mathrm{~nm}$ vs. critical diameter calculated at $0.44 \%$ supersaturation. Highlighted are data from different sampling locations and ammonium sulfate test aerosol.

of $D_{c}$ calculated for the different wind-radon regimes reveals distinct differences similar to those for the geographical sampling locations (Fig. 3b). The Gulf-Southerly Flow regime had the highest frequency of values at or less than $80 \mathrm{~nm}$ while the Inland Texas-Southerly Flow regime was just the opposite with the highest frequency of values at or greater than $90 \mathrm{~nm}$. The highest frequency of values for the Northerly Flow regime occured between 70 and $90 \mathrm{~nm}$ which spans those of the other two regimes.

\subsubsection{Relationship between HOA mass fraction and critical diameter}

The HOA mass fraction for the sub- $200 \mathrm{~nm}$ size range is plotted versus $D_{c}$ in Fig. 4 for the entire experiment and the geographical locations identified above and in Fig. 5 


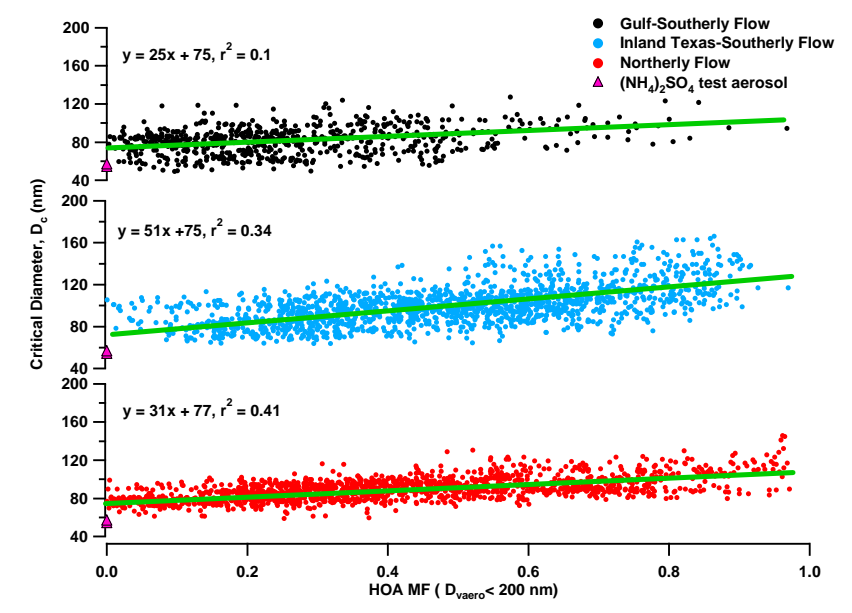

Fig. 5. HOA mass fraction of the AMS mass for the size range $D_{\text {vaero }}<200 \mathrm{~nm}$ vs. critical diameter calculated at $0.44 \%$ supersaturation. Shown are the data from the three wind-radon regimes and ammonium sulfate test aerosol.

for the three wind-radon regimes. These plots include all measurements taken at $S=0.44 \%$. Over the course of the experiment, $\mathrm{HOA}_{\mathrm{MF}}$ spanned the maximum possible range from near zero to near one. $D_{c}$ ranged from around $50 \mathrm{~nm}$, which corresponds to $D_{c}$ of ammonium sulfate at $S=0.44 \%$, to near $170 \mathrm{~nm}$. For each geographical location, an increase in $\mathrm{HOA}_{\mathrm{MF}}$ corresponded to an increase in $D_{c}$ (Fig. 4). A regression of these two parameters for all measurements made at $S=0.44 \%$ yields a coefficient of determination, $r^{2}$, of 0.4 indicating that the $\mathrm{HOA}_{\mathrm{MF}}$ explained $40 \%$ of the variance in $D_{c}$. The slope corresponds to a change in $D_{c}$ of around $40 \mathrm{~nm}$ (75 to $115 \mathrm{~nm}$ ) for the full range of $\mathrm{HOA}_{\mathrm{MF}}$ observed.

Positive correlations also were found for each of the three wind-radon regimes although the degree of correlation varied (Fig. 5). The correlation was strongest $\left(r^{2}=0.41\right)$ for the Northerly Flow regime where $\mathrm{HOA}_{\mathrm{MF}}$ varied between near zero and near one and mass concentrations were high so that the AMS signal-to-noise ratio was high. The correlation was weaker for the Inland Texas-Southerly Flow regime as concentrations were lower and signal-to-noise ratio was higher. This noise issue and the occurrence of a narrower range of $\mathrm{HOA}_{\mathrm{MF}}$ most likely contributed to a poor correlation $\left(r^{2}=0.1\right)$ for the Gulf-Southerly Flow regime.

The $\mathrm{HOA}_{\mathrm{MF}}-D_{c}$ relationship is a strong function of supersaturation. Segregating the data set by measurement supersaturation reveals a positive slope at each supersaturation but the magnitude of the slope and the $r^{2}$ values decreases with increasing supersaturation (Table 1). As the supersaturation increases, more smaller particles will activate. Hence, the change in slope may be due to a less variable particle composition (number of soluble molecules or ions per unit mass) in the lower end of Aitken size range. This response to increasing supersaturation may also be due to non-linearities
Table 1. Coefficients of linear regression for HOA and POM mass fractions $\left(D_{\text {vaero }}<200 \mathrm{~nm}\right)$ vs. critical diameter at 5 supersaturations.

\begin{tabular}{cccc}
\hline$\%$ Supersaturation & Slope & y-intercept & $r^{2}$ \\
\hline HOA Mass Fraction versus & Critical Diameter \\
0.22 & 57 & 96 & 0.5 \\
0.44 & 43 & 75 & 0.4 \\
0.65 & 32 & 64 & 0.25 \\
0.84 & 28 & 62 & 0.19 \\
1.0 & 19 & 61 & 0.08 \\
\hline POM Mass Fraction versus & Critical Diameter \\
0.22 & 38 & 94 & 0.19 \\
0.44 & 32 & 70 & 0.20 \\
0.65 & 18 & 66 & 0.09 \\
0.84 & 17 & 63 & 0.08 \\
1.0 & 12 & 61 & 0.04 \\
\hline
\end{tabular}

in the Köhler equation. For comparison, a similar regression analysis (i.e., with the data segregated by measurement supersaturation) was performed on the sub- $200 \mathrm{~nm}$ POM mass fraction and $D_{c}$. As for $\mathrm{HOA}_{\mathrm{MF}}$ versus $D_{c}$, a positive slope was found at each value of $S$ with the magnitude of the slope decreasing with increasing $\mathrm{S}$ (Table 1). However, the slope and $r^{2}$ values at each supersaturation were less than those for the $\mathrm{HOA}_{\mathrm{MF}}-D_{c}$ relationship. All $r^{2}$ values were less than or equal to 0.2 indicating only a weak correlation between POM mass fraction and $D_{c}$. Hence, the chemical properties of HOA that affect $\mathrm{CCN}$ activation are distinct from those of the bulk POM aerosol.

A multivariate factor analysis was performed to further assess the correlation between critical diameter and composition. Factor analysis often is used to separate chemical species and other relevant parameters into different groups based on their degree of covariance (e.g., Sweet and Vermette, 1992; Millet et al., 2005; Quinn et al., 2006). Parameters with a high degree of covariance are grouped together into factors. The analysis results in a loading matrix that reveals the strength of the association between parameters within and between factors. The analysis performed here was done using a principal component method with varimax rotation (SYSTAT 11, SYSTAT Software, Inc.). The goal was to test for the degree of covariance between aerosol component mass fractions $\left(\mathrm{SO}_{4}^{=}, \mathrm{NH}_{4}^{+}, \mathrm{OOA}\right.$, and $\left.\mathrm{HOA}\right)$ in the submicron and sub-200 nm size ranges and $D_{c}$ and, in particular, to determine with which variables $D_{c}$ was most strongly correlated.

Five factors explained $91 \%$ of the total variance. Factor one, which contained a high loading for $D_{c}(-0.84)$, explained $27 \%$ of the total variance in the parameters included in the factor analysis. Also highly loaded on this factor were the sub-200 $\mathrm{nm} \mathrm{HOA}(-0.90)$ and $\mathrm{SO}_{4}^{=}$mass fractions 
(+0.64), indicating a strong covariance between them and $D_{c}$. A high HOA mass fraction forced a larger $D_{c}$ value for a given supersaturation because the particle, as a whole, had fewer water soluble molecules or ions. The positive loading for the sub-200 $\mathrm{nm} \mathrm{SO}=$ mass fraction indicates an increase in soluble mass led to a decrease in $D_{c}$. Hence, the multivariate analysis confirms the strong relationship between composition and critical diameter within this data set. Factor four, which explained $15 \%$ of the total variance had a high loading for only $D_{g n}(+0.92)$ indicating it was independent from all other parameters included in the factor analysis.

3.3 Modeled sensitivity of $\mathrm{CCN}$ concentration to observed variability in composition and particle size

A model study based on Köhler theory was performed to determine to what degree calculated $\mathrm{CCN}$ concentrations would be under- or overestimated if the variability in the HOA mass fraction observed during GoMACCS was neglected. The equilibrium vapor pressure over the surface of a solution droplet is described by the Köhler Equation (e.g., Fitzgerald and Hoppel, 1984)

$S=\frac{e^{\prime}}{e_{s}}-1 \approx \frac{2 A}{d}-\frac{B d_{o}^{3}}{d^{3}}$

where $e^{\prime}$ is the equilibrium vapor pressure over the curved surface of a solution droplet, $e_{s}$ is the equilibrium vapor pressure over a flat surface of pure water,

$A=\frac{2 \sigma M_{w}}{\rho_{w} R_{v} T}$

and

$B=\frac{i \varepsilon \rho_{s} M_{w}}{\rho_{w} M_{s}}$.

Here, $d$ and $d_{o}$ are the droplet and dry particle diameters, $\sigma$ is the surface tension, $M_{w}$ and $M_{s}$ are the molecular weights of water and solute, $\rho_{w}$ and $\rho_{s}$ are the densities of water and solute, $R_{v}$ is the gas constant for water vapor, $T$ is the temperature, $i$ is the van't Hoff factor, and $\varepsilon$ is the water soluble fraction of the dry particle. By taking the first derivative of Eq. (1) with respect to diameter and finding the maximum, the following equation relating critical supersaturation $\left(S_{c}\right)$ to $D_{c}$ can be derived (e.g., Rogers and Yau, 1989; Corrigan and Novakov, 1999; Hudson, 2007)

$S_{c}=\left[\frac{32 A^{3}}{27 B}\right]^{1 / 2} D_{c}^{-3 / 2}$.

Using Eq. (5), $D_{c}$ was calculated for $S_{c}$ values of 0.22 , 0.44 , and $1.0 \%$ which correspond to three of the measurement supersaturation values $(S)$ used during the experiment. CCN concentrations for $S_{c}=0.22,0.44$, and $1.0 \%$ were calculated by integrating a modeled unimodal, log-normal size distribution over all diameters greater than the $D_{c}$ that was found to correspond to the value of $S_{c}$ using Eq. (5). Modeled size distributions were constructed using a geometric mean diameter varying between 20 and $140 \mathrm{~nm}$. For each size distribution regardless of $D_{g n}$, the total number concentration was normalized to $3000 \mathrm{~cm}^{-3}$ and the geometric standard deviation was set to 1.5. Using this method, $\mathrm{CCN}$ concentrations were calculated for a matrix $(201 \times 201)$ of insoluble mass fractions ranging from 0 to 1 and mean diameters ranging from 20 to $140 \mathrm{~nm}$.

The percent under- and overestimation of the $\mathrm{CCN}$ concentration due to neglecting the variability in the HOA mass fraction observed during GoMACCS was calculated by taking the difference between a matrix where the insoluble fraction was made constant at 0.4 for all diameters and a matrix where the insoluble mass fraction varied from 0 to 1.0 at each diameter. Hence, the base case was an insoluble mass fraction of 0.4 which corresponded to the average sub-200 $\mathrm{nm} \mathrm{HOA}_{\mathrm{MF}}$ for GoMACCS. The end result for calculated $\mathrm{CCN}$ concentrations and percent under- and overestimation of CCN concentrations is shown in Fig. 6.

Several assumptions made in this analysis warrant further discussion. Assuming that the $\mathrm{HOA}_{\mathrm{MF}}$ represents the insoluble mass fraction requires assuming not only that the measured HOA was insoluble but that all other chemical components present were fully or highly soluble. As stated above, the mass spectrum of HOA is characteristic of long chain hydrocarbons and is similar to spectra measured for fresh vehicle exhaust and lubricating oil. Based on this information, assuming that HOA is insoluble is reasonable. Furthermore, this assumption is supported by Petzold et al. (2005) who, based on measurements of combustion particles generated in a gas turbine engine, concluded that carbonaceous particles are very poor CCN. Furthermore, Saxena et al. (1995) reported that for urban aerosol, organic compounds decrease water adsorption by the inorganic fraction of the aerosol which, presumably, would lead to fewer particles being activated to CCN. Finally, based on simultaneous measurements of the hygroscopic growth factor and HOA mass concentration, Cubison et al. (2006) reported that fresh, urban aerosol emissions dominated by HOA are virtually insoluble.

The difference between the $\mathrm{HOA}_{\mathrm{MF}}$ and $D_{c}$ relationship and the POM mass fraction and $D_{c}$ relationship shown in Table 1 indicates that the HOA measured during GoMACCS had chemical properties different from the bulk POM aerosol. The result of the factor analysis $\left(D_{c}\right.$ being proportional to the $\mathrm{HOA}_{\mathrm{MF}}$ and inversely proportional to the sulfate and OOA mass fractions) indicates a similarity between the solubility of OOA and sulfate while HOA was distinctly different. Finally, measurements of marine aerosol when $\mathrm{HOA}_{\mathrm{MF}}$ were near zero and $D_{c}$ values were near that of $\left(\mathrm{NH}_{4}\right)_{2} \mathrm{SO}_{4}$ (Fig. 5 - Gulf-Southerly Flow) indicate that highly soluble aerosol was encountered during the experiment.

This analysis only includes composition effects on CCN activation that are associated with the fraction of insoluble 

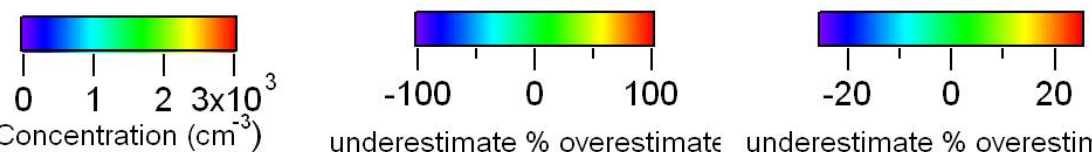

underestimate $\%$ overestimate underestimate $\%$ overestimate
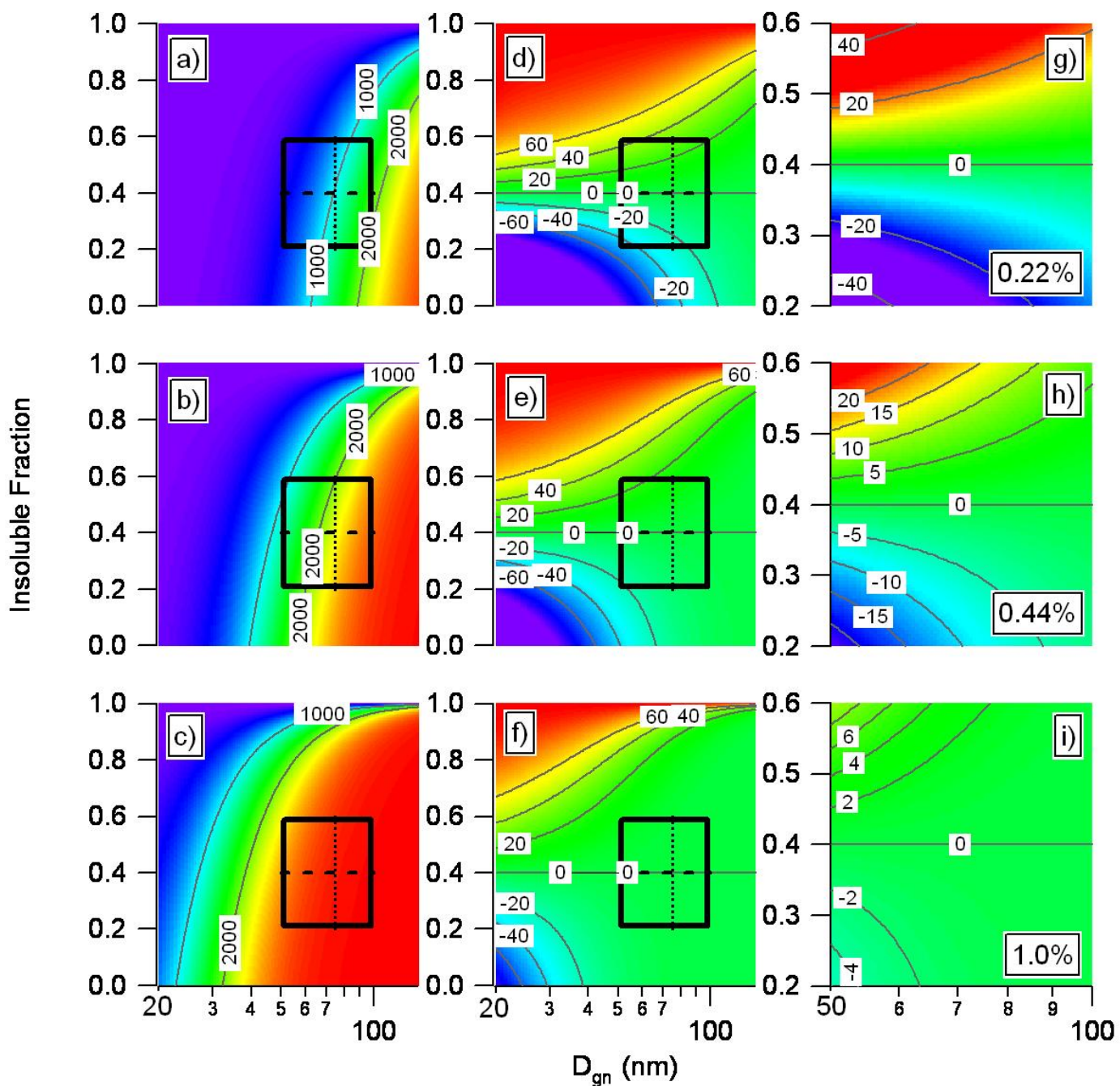

Fig. 6. Left panel shows calculated CCN concentrations based on a matrix of number-mean diameters ranging from 20 to $140 \mathrm{~nm}$ and insoluble mass fractions ranging from 0 to 1 at (a) $S=0.22 \%$, (b) $S=0.44 \%$, and (c) $S=1.0 \%$. The superimposed box represents the variability in HOA mass fraction and mean diameter observed during GoMACCS (average $\pm 1 \sigma$ standard deviation over the whole experiment). Mean HOA $_{M F}$ of 0.4 is shown as the dashed line and mean $D_{g n}$ of $75 \mathrm{~nm}$ is shown as the dotted line. Center panel shows the percent under- and overestimation of the $\mathrm{CCN}$ concentration due to neglecting the variability in the HOA $\mathrm{MF}$ observed during GoMACCS for (d) $S=0.22 \%$, (e) $S=0.44 \%$, and (f) $S=1.0 \%$. Plots were constructed by taking the difference between a matrix where the insoluble fraction was made constant at 0.4 for all diameters and a matrix where the insoluble mass fraction varied from 0 to 1 at each diameter. Right panel is the same but showing only the GoMACCS box for (g) $S=0.22 \%$, (h) $S=0.44 \%$, and (i) $S=1.0 \%$.

material in the aerosol. In principle, the model could be modified to include chemical effects such as surface tension changes. However, the lack of surface tension data for the complex composition and mixture of atmospheric aerosol encountered would make the resulting calculations highly uncertain and would not necessarily improve the result.

The combined effects of HOA mass fraction, mean diameter, and supersaturation on calculated $\mathrm{CCN}$ concentrations are shown in Fig. 6a-c. As expected, relatively few particles are activated to form $\mathrm{CCN}$ for small diameter aerosol with a large insoluble mass fraction. Conversely, most particles are activated to form $\mathrm{CCN}$ for large aerosol that is composed primarily of soluble species. Also as expected, as S increases, only the smallest particles with the smallest insoluble fraction remain unactivated. 
Table 2. Calculated CCN concentrations at three supersaturations for mean diameters of 50 and $100 \mathrm{~nm}$ and $\mathrm{HOA}_{\mathrm{MF}}$ of 0.2 and 0.6 . Also shown is the percent under- or overestimate of $\mathrm{CCN}$ concentrations for $\mathrm{HOA}_{\mathrm{MF}}$ of 0.2 and 0.6 relative to the base case of $\mathrm{HOA} \mathrm{MF}=0.4$.

\begin{tabular}{ccccllll}
\hline$S(\%)$ & $D_{g n, 1}(\mathrm{~nm})$ & $D_{g n, 2}(\mathrm{~nm})$ & $\mathrm{HOA}_{\mathrm{MF}}$ & $\begin{array}{l}\mathrm{CCN}\left(\mathrm{cm}^{-3}\right) \\
\text { at } D_{g n, 1}\end{array}$ & $\begin{array}{l}\mathrm{CCN}\left(\mathrm{cm}^{-3}\right) \\
\text { at } D_{g n, 2}\end{array}$ & $\begin{array}{l}\text { \% difference from } \\
\text { base case at } D_{g n, 1}\end{array}$ & $\begin{array}{l}\text { \% difference from } \\
\text { base case at } D_{g n, 2}\end{array}$ \\
\hline \multirow{2}{*}{0.22} & \multirow{2}{*}{50} & \multirow{2}{*}{100} & 0.2 & 368 & 2120 & -52 & -14 \\
& & & 0.6 & 125 & 1470 & +49 & +21 \\
0.44 & \multirow{2}{*}{50} & \multirow{2}{*}{100} & 0.2 & 1470 & 2860 & -25 & -3.0 \\
& \multirow{2}{*}{50} & & 0.6 & 830 & 2600 & +30 & +6.4 \\
& \multirow{2}{*}{100} & 0.2 & 2720 & 3000 & -5.3 & -0.14 \\
\hline
\end{tabular}

Superimposed on Fig. 6d-e is a box (shown expanded in Fig. $6 \mathrm{~g}-\mathrm{h}$ ) representing the range of composition and mean diameters observed during GoMACCS. Combining the measured variability with the model output allows the calculated CCN concentrations and percent under- and overestimation in calculated CCN concentrations due to neglecting the observed variability in $\mathrm{HOA}_{\mathrm{MF}}$ to be put into "real-world space". The box representing GoMACCS observed variability is based on the standard deviation $(1 \sigma)$ of the mean of the $\mathrm{HOA}_{\mathrm{MF}}$ and $D_{g n}$ averaged over the entire experiment. Hence, it is a conservative estimate of the variability and does not include the full range of values observed. The modeled $\mathrm{CCN}$ concentrations and percent under- and overestimation in calculated $\mathrm{CCN}$ concentrations for each corner of the GoMACCS box relative to the base case of an $\mathrm{HOA}_{\mathrm{MF}}$ of 0.4 are reported in Table 2.

Calculated $\mathrm{CCN}$ concentrations corresponding to the range of observed variability in $\mathrm{HOA}_{\mathrm{MF}}$ (insoluble mass fraction) are a strong function of supersaturation and mean diameter (Fig. 6a-c and Table 1). Figure 6a shows that, for $S=0.22 \%$ and $D_{g n}=50 \mathrm{~nm}$, an increase in the $\mathrm{HOA}_{\mathrm{MF}}$ from 0.2 to 0.6 results in a decrease in $\mathrm{CCN}$ concentration from 368 to $125 \mathrm{~cm}^{-3}$ or a decrease of $66 \%$. In contrast, Fig. $6 \mathrm{c}$ shows that for $S=1.0 \%$ and $D_{g n}=50 \mathrm{~nm}$, the same increase in $\mathrm{HOA}_{\mathrm{MF}}$ results in a decrease in the $\mathrm{CCN}$ concentration of only $14 \%$. At $S=0.22$ and $1.0 \%$ and $D_{g n}=100 \mathrm{~nm}$, the change in $\mathrm{HOA}_{\mathrm{MF}}$ from 0.2 to 0.6 results in a decrease in $\mathrm{CCN}$ concentration of 31 and $<1 \%$, respectively. Figure $6 \mathrm{~d}-\mathrm{f}$ shows the percent under- and overestimation in calculated $\mathrm{CCN}$ concentrations due to neglecting the variability in $\mathrm{HOA}_{\mathrm{MF}}$ (insoluble mass fraction) observed during GoMACCS. The GoMACCS box is superimposed on Fig. $6 \mathrm{~d}-\mathrm{f}$ and expanded and plotted full-scale in Fig. $6 \mathrm{~g}-\mathrm{i}$. At $S=0.22 \%$ and a mean $D_{g n}$ of $50 \mathrm{~nm}$, an increase in the $\mathrm{HOA}_{\mathrm{MF}}$ from the base case of 0.4 to the $+1 \sigma$ standard deviation of 0.6 results in an overestimation of the $\mathrm{CCN}$ concentration by $49 \%$ (Table 1). A decrease to the $-1 \sigma$ standard deviation of 0.2 results in an underestimation of $52 \%$. For the same supersaturation but a mean $D_{g n}$ of $100 \mathrm{~nm}$, an increase in the $\mathrm{HOA}_{\mathrm{MF}}$ from 0.4 to 0.6 results in a $21 \%$ overestimation in the $\mathrm{CCN}$ concentra- tion while a decrease from 0.4 to 0.2 results in a $14 \%$ underestimation. At $S=1.0 \%$, the same changes in $\mathrm{HOA}_{\mathrm{MF}}$ result in minimal under- or overestimates in the $\mathrm{CCN}$ concentration of $\leq 10 \%$. Overall, for the variability in composition observed during GoMACCS, the impact on the calculated CCN concentration of neglecting the variability in the observed $\mathrm{HOA}_{\mathrm{MF}}$ is significant for $S=0.44 \%$ and lower.

\subsection{Calculated $\mathrm{CCN}$ concentrations as a function of aerosol history}

A more detailed presentation of data from GoMACCS is shown superimposed on the modeled percent under- and overestimation of $\mathrm{CCN}$ concentration plots in Fig. 7. Here, average mean $D_{g n}$ values are plotted versus $\mathrm{HOA}_{\mathrm{MF}}$ for the specific geographical sampling locations and for the three wind-radon regimes. The lowest $\mathrm{HOA}_{\mathrm{MF}}$ and largest sub$200 \mathrm{~nm}$ mean diameters correspond to the Atlantic Marine and Gulf of Mexico sampling locations as well as the GulfSoutherly Flow wind-radon regime. Aerosol in each of these cases was sampled away from continental anthropogenic sources and had a sub- $200 \mathrm{~nm}$ composition dominated by sulfate and/or OOA; the $\mathrm{HOA}_{\mathrm{MF}}$ was less than 0.2 at some diameters. At $S=0.22 \%$, the percent underestimation in calculated $\mathrm{CCN}$ concentrations relative to the base case of an $\mathrm{HOA}_{\mathrm{MF}}$ (insoluble mass fraction) of 0.4 ranged from greater than $60 \%$ for Atlantic Marine to between 20 and $40 \%$ for the Gulf of Mexico and Gulf-Southerly Flow regime.

By comparison, model CCN concentrations were overestimated for sampling locations next to continental anthropogenic sources (Barbours Cut, Galveston Bay, Houston Ship Channel). In addition, CCN concentrations were overestimated for the Inland-Southerly Flow regime, where the aerosol was a result of local industrial and urban sources and background Gulf of Mexico aerosol, and for the Northerly Flow regime which was impacted by both near and distant anthropogenic sources. The highest $\mathrm{HOA}_{\mathrm{MF}}$ were observed at Barbours Cut and during the Inland-Southerly Flow regime for mean diameters less than $60 \mathrm{~nm}$. As a result, $\mathrm{CCN}$ concentrations were overestimated by greater than $60 \%$. For 


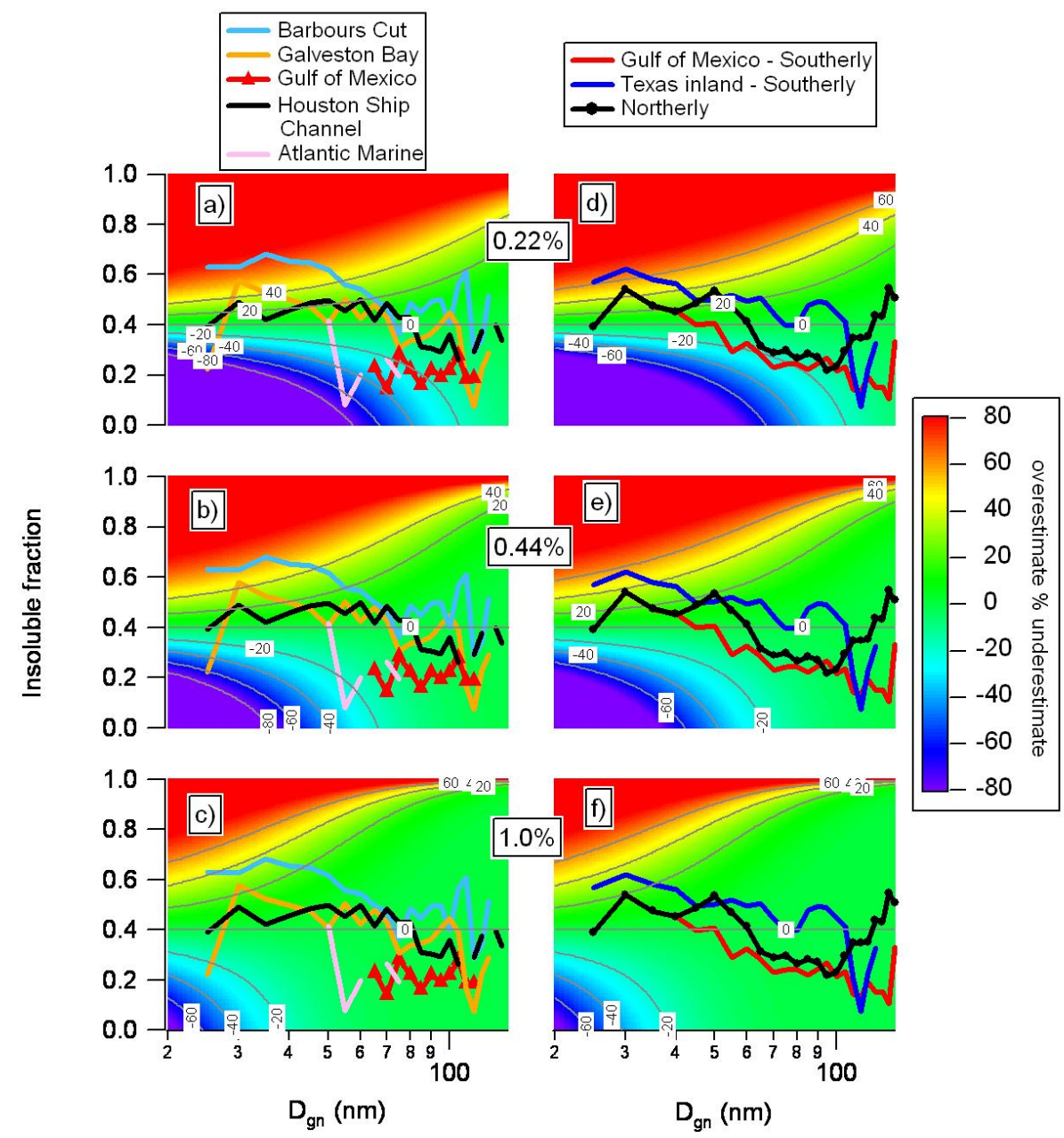

Fig. 7. The percent under- and overestimation of the $\mathrm{CCN}$ concentration due to neglecting the variability in the $\mathrm{HOA}_{\mathrm{MF}}$ observed during GoMACCS for $S=0.22 \%, S=0.44 \%$, and $S=1.0 \%$. Plots were constructed by taking the difference between a matrix where the insoluble fraction was made constant at 0.4 for all diameters and a matrix where the insoluble mass fraction varied from 0 to 1 at each diameter. Superimposed on the figure is the average $D_{g n}$ versus $\mathrm{HOA}_{\mathrm{MF}}$ for the geographic locations (left panel) and wind-radon regimes (right panel).

larger mean diameters (between 70 and $120 \mathrm{~nm}$ ), the HOA $\mathrm{MF}_{\mathrm{M}}$ was still sufficiently large relative to the base case value of 0.4 to result in an overprediction of $\mathrm{CCN}$ concentrations up to $20 \%$.

\section{Conclusions}

The mass fraction of HOA in the $D_{\text {vaero }}<200 \mathrm{~nm}$ size range was used to represent the observed variability in chemical composition during GoMACCS and to assess the sensitivity of $\mathrm{CCN}$ activation to composition. For sampling locations impacted by urban, industrial, and marine vessel emissions, HOA dominated the mass in the sub- $200 \mathrm{~nm}$ size range. A regression of the sub-200 $\mathrm{nm} \mathrm{HOA}_{\mathrm{MF}}$ versus critical diameter for all measurements made at $0.44 \% S$ resulted in an $r^{2}$ value of 0.4 indicating that HOA could explain $40 \%$ of the variance in $D_{c}$. An increase in the $\mathrm{HOA}_{\mathrm{MF}}$ from 0 to 1 corresponded to an increase in $D_{c}$ of $40 \mathrm{~nm}$.

Model calculations, which assumed that HOA was completely insoluble, were performed to determine the percent under- or overestimation in the calculated $\mathrm{CCN}$ concentration if the variability in the $\mathrm{HOA}_{\mathrm{MF}}$ observed during GoMACCS were neglected. The mean $\mathrm{HOA}_{\mathrm{MF}}$ over the entire experiment was 0.4 with a $1 \sigma$ standard deviation of \pm 0.2 . At a mean diameter of $50 \mathrm{~nm}$ and a supersaturation of $0.22 \%$, neglecting the $1 \sigma$ standard deviation resulted in an under- or overestimation of the $\mathrm{CCN}$ concentration of about $50 \%$. Percent overestimations of $\mathrm{CCN}$ concentrations were largest for aerosol sampled from inland locations in close proximity to anthropogenic sources due to higher $\mathrm{HOA}_{\mathrm{MF}}$ but still considerable for aerosol sampled further offshore in the Gulf of Mexico. 
The calculations presented here did not include other chemical effects of the HOA on CCN activation (e.g., surface tension) due to a lack of information about the chemical properties of the HOA. They were able, however, to indicate the importance of considering the unique composition of the sub-200 $\mathrm{nm}$ size range which is the size range where chemical effects are most pronounced in CCN activation and where the majority of the observed HOA is found. In addition, the unique combination of measurements and model calculations presented here serve to relate errors in $\mathrm{CCN}$ calculations to observed variability in aerosol composition and size. Further measurements of the chemical composition in this size range and in different geographical regions are required to refine the calculations presented here.

Acknowledgements. This work was supported by the NOAA Climate Program Office, the NOAA Health of the Atmosphere Program, and the Texas Air Quality Study. We thank D. Hamilton, J. Johnson, K. Schulz, C. Hoyle and the officers and crew of the Ronald H. Brown for logistical, technical, and scientific support. This is PMEL contribution number 3136.

Edited by: J. Curtius

\section{References}

Abdul-Razzak, H. and Ghan, S. J.: A parameterization of aerosol activation 3. Sectional representation, J. Geophys. Res., 107(D3), 4026, doi:10.1029/2001JD000483, 2002.

Alfarra, M. R., Coe, H., Allan, J. D., et al.: Characterization of urban and rural organic particulate matter in the lower Fraser valley using two Aerodyne mass spectrometers, Atmos. Environ., 38, 5745-5758, 2004.

Allan, J. D., Alfarra, M. R., Bower, K. N., et al.: Quantitative sampling using an Aerodyne aerosol mass spectrometer. Part 2: Measurements of fine particulate chemical composition in two UK cities, J. Geophys. Res., 108, 4091, doi:410.1029/2002JD002359, 2003.

Bates, T. S., Coffman, D. J., Covert, D. S., and Quinn, P. K.: Regional marine boundary layer aerosol size distributions in the Indian, Atlantic and Pacific Oceans: A comparison of INDOEX measurements with ACE-1, ACE-2, and Aerosols99, J. Geophys. Res., 107(D19), 8026, doi:10.1029/2001JD001174, 2002.

Bates, T. S., Quinn, P. K., Coffman, D. J., et al.: Marine boundary layer dust and pollutant transport associated with the passage of a frontal system over eastern Asia, J. Geophys. Res., 109, D19S19, doi:10.1029/2003JD004094, 2004.

Berner, A., Lurzer, C., Pohl, F., Preining, O., and Wagner, P.: The size distribution of the urban aerosol in Vienna, Sci. Total Environ., 13, 245-261, 1979.

Boudries, H., Canagaratna, M. R., Jayne, J. T., et al.: Chemical and physical processes controlling the distribution of aerosols in the Lower Fraser Valley, Canada during the PACIFIC 2001 field campaign, Atmos. Environ., 38, 5759-5774, 2004.

Canagaratna, M. R., Jayne, J. T., Ghertner, D. A., et al.: Chase studies of particulate emissions from in-use New York city vehicles, Aerosol Sci. Tech., 38, 555-573, 2004.
Canagaratna, M. R., Jayne, J. T., Jimenez, J. L., et al.: Chemical and microphysical characterization of ambient aerosols with the Aerodyne Aerosol Mass Spectrometer, Mass Spectrom. Rev., 26, 185-222, 2007.

Corrigan, C. E. and Novakov, T.: Cloud condensation nucleus activity of organic compounds: a laboratory study, Atmos. Environ., 33, 2661-2668, 1999.

Cubison, M. J., Alfarra, M. R., Allan, J., Bower, K. N., Coe, H., McFiggans, G. B., Whitehead, J. D., Williams, P. I., Zhang, Q., Jimenez, J. L., Hopkins, J., and Lee, J.: The characterisation of pollution aerosol in a changing photochemical environment, Atmos. Chem. Phys., 6, 5573-5588, 2006, http://www.atmos-chem-phys.net/6/5573/2006/.

Drewnick, F., Schwab, J. J., Jayne, J. T., Canagaratna, M., Worsnop, D. R., and Demergian, K. L.: Measurement of ambient aerosol composition during the PMTACS-NY 2001 using an Aerosol Mass Spectrometer, Part II: Chemically speciated mass distributions, Aerosol Sci. Tech., 38, 104-117, 2004.

Dusek, U., Frank, G. P., Hildebrandt, L., et al.: Size matters more than chemistry for cloud-nucleating ability of aerosol particles, Science, 312, 1375-1376, 2006.

Ervens, B., Feingold, G., and Kreidenweis, S. M.: The influence of water-soluble organic carbon on cloud drop number concentration, J. Geophys. Res., 110, 18211, doi:10.1029/2004JD005634, 2005.

Feingold, G.: Modeling of the first indirect effect: Analysis of measurement requirements, Geophys. Res. Lett., 30, 1997, doi:10.1029/2003GL017967, 2003.

Fitzgerald, J. W. and Hoppel, W. A.: Equilibrium size of atmospheric aerosol particles as a function of relative humidity: Calculations based on measured aerosol properties, in: Hygroscopic Aerosols, edited by: Ruhnke, L. H. and Deepak, A., A. Deepak, Hampton, VA, 21-34, 1984.

Fountoukis, C. and Nenes, A.: Continued development of a cloud droplet formation parameterization for global climate models, J. Geophys. Res., 110, 11212, doi:10.1029/2003JD004324, 2005.

Hudson, J.: Variability of the relationship between particle size and cloud-nucleating ability, Geophys. Res. Lett., 34, L08801, doi:10.1029/2006GL028850, 2007.

Huffman, J. A., Jayne, J. T., Drewnick, F., Aiken, A. C., Onasch, T., Worsnop, D. R., and Jimenez, J. L.: Design, Modeling, Optimization, and Experimental Tests of a Particle Beam Width Probe for the Aerodyne Aerosol Mass Spectrometer, Aerosol Sci. Tech., 39, 1143-1163, 2005.

IPCC (Intergovernmental Panel on Climate Change): Radiative forcing of climate change, in Climate Change 2001, Cambridge Univ. Press, New York, Cambridge University Press, 2001.

IPCC (Intergovernmental Panel on Climate Change): Changes in Atmospheric Constituents and in Radiative Forcing, in: The IPCC 4th Assessment Report, 2007.

Lance, S., Medina, J., Smith, J. N., and Nenes, A.: Mapping the operation of the DMT continuous flow CCN counter, Aerosol Sci. Tech., 40, 242-254, 2006.

Maßling, A., Wiedensohler, A., Busch, B., Neusuß, C., Quinn, P., Bates, T., and Covert, D.: Hygroscopic properties of different aerosol types over the Atlantic and Indian Oceans, Atmos. Chem. Phys., 3, 1377-1397, 2003, http://www.atmos-chem-phys.net/3/1377/2003/.

McFiggans, G., Artaxo, P., Baltensperger, U., Coe, H., Facchini, M. 
C., Feingold, G., Fuzzi, S., Gysel, M., Laaksonen, A., Lohmann, U., Mentel, T. F., Murphy, D. M., O’Dowd, C. D., Snider, J. R., and Weingartner, E.: The effect of physical and chemical aerosol properties on warm cloud droplet activation, Atmos. Chem. Phys., 6, 2593-2649, 2006, http://www.atmos-chem-phys.net/6/2593/2006/.

Mircea, M., Facchini, M. C., Decesari, S., Fuzzi, S., and Charlson, R. J.: The influence of the organic aerosol component on CCN supersaturation spectra for different aerosol types, Tellus B, 54, 74-81, 2002.

Nenes, A., Charlson, R. J., Facchini, M. C., Kulmala, M., Laaksonen, A., and Seinfeld, J. H.: Can chemical effects on cloud droplet number rival the first indirect effect?, Geophys. Res. Lett., 29, 1848, doi:10.1029/2002GL015295, 2002.

Petzold, A., Gysel, M., Vancassel, X., Hitzenberger, R., Puxbaum, H., Vrochticky, S., Weingartner, E., Baltensperger, U., and Mirabel, P.: On the effects of organic matter and sulphurcontaining compounds on the $\mathrm{CCN}$ activation of combustion particles, Atmos. Chem. Phys., 5, 3187-3203, 2005,

http://www.atmos-chem-phys.net/5/3187/2005/.

Quinn, P. K., Coffman, D. J., Bates, T. S., Miller, T. L., Johnson, J. E., Welton, E. J., Neusüss, C., Miller, M., and Sheridan, P.: Aerosol optical properties during INDOEX 1999: Means, variabilities, and controlling factors, J. Geophys. Res., 107(D19), 8020, doi:10.1029/2000JD000037, 2002.

Quinn, P. K., Coffman, D. J., Bates, T. S., Welton, E. J., Covert, D. S., Miller, T. L., Johnson, J. E., Maria, S., Russell, L., Arimoto, R., Carrico, C. M., Rood, M. J., and Anderson, J.: Aerosol Optical Properties Measured Onboard the Ronald H. Brown During ACE Asia as a Function of Aerosol Chemical Composition and Source Region, J. Geophys. Res., 109, D19S01, doi:10.1029/2003JD004010, 2004.

Roberts, G. C. and Nenes, A.: A continuous-flow streamwise thermal gradient $\mathrm{CCN}$ chamber for atmospheric measurements, Aerosol Sci. Tech., 39, 206-221, 2005.
Rogers, R. R. and Yau, M. K.: A Short Course in Cloud Physics, Elsevier, New Yori, 1989.

Saxena, P., Hildemann, L. M., McMurry, P. H., and Seinfeld, J. H.: Organics alter hygroscopic behavior of atmospheric particles, J. Geophys. Res., 100, 18 755-18 770, 1995.

Schneider, J., Hock, N., Weimer, S., Borrmann, S., Kirchner, R., Vogt, R., and Scheer, V.: Nucleation particles in diesel exhaust: Composition inferred from in situ mass spectrometric analysis, Environ. Sci. Tech., 39, 6153-6161, 2005.

Shantz, N. C., Leaitch, W. R., and Caffrey, P. F.: Effect of organics of low solubility on the growth rate of cloud droplets, J. Geophys. Res., 108, 4168, doi:10.1029/2002JD002540, 2003.

Stratmann, F. and Wiedensohler, A.: A new data inversion algorithm for DMPS measurements, J. Aerosol Sci., 27, 339-340, 1997.

Twomey, S.: The influence of pollution on the shortwave albedo of clouds, J. Atmos. Sci., 34, 1149-1152, 1977.

Whittlestone, S. and Zahorowski, W.: Baseline radon detectors for shipboard use: Development and deployment in the First Aerosol Characterization Experiment (ACE 1), J. Geophys. Res., 103, 16743-16 751, 1998.

Winklmeyer, W., Reischl, G. P., Lindner, A. O., and Berner, A.: New electromobility spectrometer for the measurement of aerosol size distributions in the size range 1 to $1000 \mathrm{~nm}, \mathrm{~J}$. Aerosol Sci., 22, 289-296, 1991.

Zhang, Q., Alfarra, M. R., Worsnop, D. R., Allan, J. D., Coe, H., Canagaratna, M. R., and Jimenez, J. L.: Deconvolution and quantification of hydrocarbon-like and oxygenated organic aerosols based on aerosol mass spectrometry, Environ. Sci. Tech., 39, 4938-4952, doi:10.1021/es0485681, 2005a.

Zhang, Q., Worsnop, D. R., Canagaratna, M. R., Jayne, J. T., and Jimenez, J. L.: Hydrocarbon-like and oxygenated organic aerosols in Pittsburgh: Insights into sources and processes of organic aerosols, Atmos. Chem. Phys., 5, 3289-3311, 2005 b. 